\title{
Prevenção integrada: novas perspectivas para as políticas de segurança no Brasil
}

\section{Integrated prevention: new perspectives for public safety policies in Brazil}

\section{esumo}

O presente artigo busca identificar os elementos constitutivos de uma nova perspectiva de tratamento da conflitualidade social contemporânea. Parte-se do reconhecimento dos limites do paradigma reativo, característico da modernidade em matéria penal, pautado pela lógica formal e dogmática da normatividade estatal. Se de um lado a crise deste paradigma leva ao recrudescimento do punitivismo, com propostas de aumento de penas e da utilização das mesmas não mais para retribuir ao delito ou reinserir o indivíduo na sociedade, mas como mecanismo de pura e simples contenção, e à supressão de garantias em nome da eficiência e do combate ao crime, de outro, surgem por toda parte experiências de gestão da segurança baseadas na participação cidadã e no engajamento da sociedade civil em políticas de inclusão social e controle público da atuação da polícia e do sistema penal.

Palavras-chave: violência, segurança pública, políticas públicas, prevenção.

\section{As bstract}

This article seeks to identify the elements that are establishing a new perspective in the handling contemporary social conflicts. It is based on the recognition of the limits of the reactive paradigm, characteristic of modernity in relation to criminal issues, which is based on the formal and dogmatic logic of government normativity. On one hand the crisis in this paradigm has led to the reappearance of a punitive approach, and proposals to increase punishments that are no longer seen as a retribution for a crime or a way to reinsert the individual into society. Punishments have often become mechanisms of pure and simple contention and suppression of rights in name of efficiency and combating crime. On the other hand, many experiences are appearing in public safety administration based on citizen participation, and on the engagement of civil society in policies for social inclusion and public control of police activity and of the penal system.

Key words: violence, public safety, public policies, prevention.

\section{Rodrigo Ghiringhelli de Azevedo}

Doutor em Sociologia.

Professor dos Programas de Pós-Graduação em Ciências Criminais e Ciências Sociais da PUCRS. 
0 referendo de 23 de outubro de 2005, ao colocar em pauta o tema da comercialização de armas de fogo no Brasil, trouxe ao debate público uma questão que, segundo as pesquisas de opinião, tem cada vez mais tirado o sono de grande parte da população brasileira: a criminalidade violenta e o funcionamento dos órgãos responsáveis pela segurança pública no Brasil.

Se em alguma medida o medo e a sensação de insegurança são fruto não de um efetivo aumento das chances de vitimização, mas do aumento da percepção social acerca dos fatos violentos, fenômeno derivado de uma cultura da "virtualidade real" na qual estamos inseridos (CASTELLS, 1999, p. 353), o fato é que a chamada criminalidade urbana violenta vem crescendo no Brasil de forma ininterrupta desde o final da década de 1970, crescimento este bem superior ao padrão de crescimento populacional no mesmo período. Delitos como o homicídio, o roubo e a extorsão mediante seqüestro, tornaram-se fatos corriqueiros no cotidiano das grandes e médias cidades brasileiras, afetando a vida de milhares de pessoas (ADORNO, 1998, p. 230).

Confrontadas com os indicadores de criminalidade violenta em outros países, as estatísticas de homicídios no Brasil apontam para níveis alarmantes, atingindo especialmente a população masculina jovem, entre 15 e 24 anos, moradora das periferias dos grandes centros urbanos. $\mathrm{O}$ mesmo se pode dizer em relação aos delitos contra o patrimônio, geralmente cometidos mediante ameaça contra a pessoa, e da violência no ambiente doméstico, vitimizando mulheres e crianças de forma costumeira.

Juntamente com o crescimento nas taxas de criminalidade violenta, um outro componente contribui de forma decisiva para o descrédito nas instituições e a busca de alternativas privadas para a garantia da segurança. Trata-se do baixo padrão de funcionamento do sistema de justiça criminal. Uma análise de cada uma das agências que compõem o sistema, em geral ineficientes ou despreparadas para atuar em padrões satisfatórios de legalidade, permite compreender os motivos que levam boa parte da população a perceber o contexto social como um verdadeiro estado de natureza (ADORNO, 1998, p. 237).

O impacto da violência criminal sobre o tecido social e a incapacidade dos órgãos estatais em responder de forma minimamente eficiente e juridicamente correta às demandas de controle do crime começaram a chamar a aten- ção dos cientistas sociais já na década de 1980, com a criação do Núcleo de Estudos da Violência, na Universidade de São Paulo, e os trabalhos desenvolvidos pela antropóloga Alba Zaluar (1998, 2004), nas favelas do Rio de Janeiro. Nos anos 90, os estudos sobre a violência e a segurança pública deixaram de ser uma quase exclusividade dos estudiosos do Direito Penal, e passaram a constituir um dos campos mais destacados da produção acadêmica no âmbito de programas de pós-graduação em Sociologia, Antropologia, Ciência Política ou mesmo interdisciplinares, com a criação de grupos de pesquisa em vários cantos do país (KANT DE LIMA; MISSE; MIRANDA, 2000).

Com base nestes estudos, dispomos hoje de um importante acervo de pesquisas, baseadas em diferentes perspectivas teórico-metodológicas, que permitem avançar em algumas conclusões sobre os caminhos a serem trilhados no enfrentamento de um problema cujas vias de equacionamento estão inexoravelmente vinculadas às possibilidade de construção democrática no Brasil. Deixar em segundo plano o problema da violência e da segurança pública, com todas as suas implicações, ou acreditar que a solução passa exclusivamente pelo sistema de justiça criminal, significa hoje contribuir para o descrédito das instituições e a desagregação do tecido social.

Por outro lado, acreditar que o problema da violência é derivado exclusivamente da dinâmica excludente da economia capitalista, e que nada pode ser feito até que uma nova forma de organização da produção e distribuição de riquezas seja constituída, só contribui para a aceitação passiva das políticas de Estado social mínimo e Estado penal máximo que caracterizam este início de milênio por todo o mundo (WACQUANT, 2001).

A emergência da modernidade no âmbito do controle penal constituiuse com base na idéia de que o controle do crime deveria ser levado a efeito por especialistas, orientado para a identificação e o processamento dos fatos previstos em lei como delitos e a punição dos criminosos, sem a necessidade de envolvimento do público ou das vítimas individuais. Tudo o que se necessitava era um marco legal abstrata e logicamente erigido e uma resposta reativa ao delito, num contexto ideológico de crença na solução dos problemas sociais através de burocracias especializadas, dirigidas pelo Estado, formadas por peritos e racionalmente direcionadas (GARLAND, 2001). 
No momento atual, caracterizado pela crise dos parâmetros fundantes da modernidade para a estruturação das relações entre Estado e sociedade civil, a manutenção de um paradigma reativo, pautado pela lógica formal e dogmática da normatividade estatal, se de alguma forma contribui para rechaçar os abusos por parte do poder punitivo do Estado frente aos direitos e garantias dos cidadãos, precisa ser urgentemente complementada por uma nova perspectiva de tratamento da conflitualidade social contemporânea.

É preciso, em primeiro lugar, reconhecer os limites do Estado contemporâneo para garantir o monopólio da violência legítima. Se em algum momento essa pretensão se efetivou, de forma mais ou menos ampla, nos países beneficiários do processo de acumulação capitalista, na periferia do sistema essa pretensão sempre foi minada, de um lado, pela falta de legitimidade da normatividade estatal e, de outro, pela manutenção de mecanismos tradicionais de controle social por meio da violência física ou simbólica institucionalizada. Hoje, o desenvolvimento das redes de criminalidade organizada e transnacional, em torno de mercadorias ilegais, mas amplamente demandadas como drogas e armas, e o crescimento da criminalidade urbana violenta, difusa e disseminada, colocam em questão, mesmo nos países centrais, a possibilidade de garantia da ordem pública por meio dos mecanismos estatais de controle do crime (ADORNO, 2002, p. 272).

A falência da capacidade de resposta do sistema penal, vítima de uma evidente sobrecarga de expectativas, e a decorrente ilegitimidade que daí decorre, já que não desempenha de maneira satisfatória as funções de prevenção geral e especial que o justificam, têm levado os chamados movimentos de lei e ordem a pedirem sempre mais do mesmo, ou seja: "já que o remédio não funciona, vamos aumentar a dose". O perigo, obviamente, é matar o paciente...

Em nome dos clamores midiáticos por mais segurança, propõe-se a redução da impunidade e das margens de tolerância; o aumento de penas e a utilização das mesmas não mais para retribuir o delito ou reinserir o indivíduo na sociedade, mas como mecanismo de pura e simples contenção; a supressão de garantias em nome da eficiência e do combate ao crime; a busca de alternativas individuais, como a segurança privada e a auto-defesa, que minam ainda mais a capacidade de uma resposta coletiva e democrática. Em nome da defesa da sociedade contra o crime, são postas de lado as conquistas civilizatórias no âmbito do sistema penal, pilares fundamentais de uma sociedade que se pretenda democrática, e a defesa dos direitos humanos passa a ser tachada como a "defesa de bandidos".

Em uma sociedade hierárquica e desigual como a brasileira, em que as relações sociais são pautadas não pelo princípio da igualdade, mas por relações de clientelismo e compadrio, o criminoso é visto sempre como o "outro", aquele que não está ao abrigo da lei e do direito, e deve ser submetido ao arbítrio e à violência que a própria sociedade exige dos agentes do sistema. Por isso, não há, historicamente, maior preocupação com os abusos cometidos pelas polícias militares, cujas funções foram sempre vinculadas ao controle das "classes perigosas", e não à garantia dos direitos individuais. Por isso, a produção de provas pela Polícia Civil é feita com base em depoimentos pessoais, "confissões" obtidas a portas fechadas, e não há investimento efetivo e permanente em técnicas mais avançadas de obtenção de provas. Por isso o sistema prisional é um espetáculo de horrores, que não choca a opinião pública e não comove os governantes, porque é exatamente isso o que se espera dele: a expiação da culpa, o sofrimento, a punição do corpo e da alma dos depositários das nossas mazelas sociais.

Mas, se de um lado este cenário de medo e intolerância viceja por toda parte, não é menos verdade que novas alternativas são gestadas, geralmente envolvendo os mais diversos atores sociais, que em meio à intempérie vão inventando formas mais eficazes, democráticas e dialogais para lidar com o conflito, a revolta e a violência. Nessa gestação de mecanismos de pacificação social, a dicotomia entre público e privado perde espaço, sobreposta pela dinâmica de constituição de uma esfera pública não estatal, onde os agentes do Estado atuam como motivadores, facilitadores ou indutores de um processo amplo de mobilização da sociedade civil (ZACCHI, 2002).

Seja por meio da atuação de associações comunitárias, igrejas, empresas ou ong's, ou ainda pela criação de conselhos comunitários com a participação direta dos cidadãos e lideranças comunitárias, as redes sociais vão se formando e alimentando novas práticas de gestão da conflitualidade social, menos pautadas pela punição, mais abertas ao reconhecimento das diferenças e à construção de novas formas de convivência, pautadas pela reciprocidade.

Fazem parte deste caminho alternativo os processos de municipalização da gestão da segurança. A partir de uma compreensão de que a violência e o crime são fenômenos que derivam de um contexto global, mas acontecem no local, evidencia-se a necessidade de que os gestores das políticas públicas de segurança estejam mais próximos do problema, e mais capacitados para atuar como propulsores de um processo de resgate da participação cidadã na discussão e no equacionamento dos problemas sociais. Em um grande número de municípios por todo o país, a criação das secretarias municipais de segurança urbana tem oportunizado a abertura de um canal de conexão mais próximo e efetivo entre governantes e sociedade, viabilizando a implementação de novas práticas micro-sociais de equacionamento dos conflitos que, se não enfrentados, contribuem para gerar o sentimento de insegurança e anomia social.

Fazem parte deste âmbito de iniciativas os programas de inclusão social para jovens de baixa renda, que começam com políticas de transformação do espaço escolar, 
capacitando os professores para lidar com maior competência com a diversidade de valores e experiências dos alunos e com a complexidade do contexto social onde a escola está inserida. E vão até as oficinas de rap e o incentivo às práticas esportivas, os programas de inclusão digital e de geração de renda, os cursos voluntários de preparação ao vestibular e os núcleos de formação em direitos e cidadania, que se desenvolvem de forma transversal, conectando diferentes atores e constituindo na prática as malhas de novas redes de solidariedade social.

Também compõem esta perspectiva de enfrentamento os programas de melhoria do ambiente urbano, fundamentais para o resgate da dignidade e da responsabilidade cidadã e comunitária. Aregularização fundiária de moradias de baixa renda, combinada com a intervenção efetiva do Estado para a garantia dos equipamentos públicos necessários ao convívio social e à garantia de direitos, como os Centros Integrados de Cidadania, em São Paulo, ou os Centros de Referência e Apoio às Vítimas da Violência, buscando muitas vezes parcerias com empresas que assumem sua responsabilidade social, tem trazido resultados efetivos na melhoria dos índices de qualidade de vida em várias regiões, e a redução das taxas de violência e dos danos por ela causados.

Juntamente com essas políticas sociais, as políticas públicas de segurança, elaboradas em parceria por prefeituras, agências policiais, associações de moradores e demais atores sociais, têm apostado em mecanismos de redução das oportunidades para o delito, tendo como referência a idéia de que prevenir é melhor do que punir. Programas de redução do consumo de álcool e de drogas, pautados pela perspectiva da redução dos danos e pela adesão voluntária, trazem resultados efetivos na redução da violência doméstica e interpessoal. Soluções mais drásticas, como a adotada em Diadema, como o fechamento de bares a partir das 23 horas, para impedir a comercialização de bebidas e drogas, ou as câmeras de vigilância em determinadas áreas de maior circulação de pessoas, podem ser adotadas, de forma provisória e experimental, uma vez que se constatem os efeitos desses dispositivos para a desconstituição dos mecanismos de agenciamento da violência.

A política de controle rigoroso sobre o armamento, viabilizada com a aprovação do Estatuto do Desarmamen- to, também é importante fator de redução das oportunidades para desfechos fatais em conflitos cotidianos, e já traz resultados alentadores no número de internações por ferimento com arma de fogo. Nesse sentido, a derrota da proibição à comercialização de armas de fogo e munição no referendo, se de alguma forma fragiliza a implementação de um controle mais efetivo, não impede que se dê prioridade ao controle sobre o porte ilegal e se mantenha o rigor necessário para limitar a aquisição de armas aos casos estritamente definidos em lei.

No âmbito do sistema de segurança pública, a melhor preparação das polícias para atuar em democracia é uma exigência inafastável, e que tem sido incorporada em diversos estados pelos gestores da segurança, e incentivada pelos reiterados Planos Nacionais de Segurança Pública e pelos representantes do Governo Federal, através da Secretaria Nacional de Segurança Pública, em que pese todos os percalços na implementação de políticas permanentes de formação, capacitação e aparelhamento das polícias civis e militares. As experiências de policiamento comunitário, a criação de uma base curricular unificada para a formação das polícias, incorporando o tema dos direitos humanos, as técnicas de policiamento preventivo e de mediação de conflitos, o investimento em inteligência para atuar contra o crime organizado e a lavagem de dinheiro, e o combate à corrupção policial, são questões incorporadas à agenda dos gestores públicos da segurança, e que devem ser permanentemente cobradas pela sociedade.

No tocante ao funcionamento do sistema de justiça penal, as altas taxas de impunidade, a morosidade e seletividade da justiça, as condições de superlotação e precariedade do sistema prisional ainda exigem um enfrentamento mais efetivo, que deve ter como ponto de inflexão a crítica à expansão punitiva e o combate à idéia de que se pode resolver problemas sociais por meio do sistema penal.

Juntamente com o ideário garantista de um direito penal mínimo, e da preocupação permanente com a garantia dos direitos do indivíduo frente ao poder punitivo do Estado, é preciso também investir nas novas possibilidades de tratamento do delito, abertas com a criação dos Juizados Especiais Criminais. A ampliação do espaço de mediação no interior dos Juizados, vinculada a uma perspectiva de Justiça Restaurativa ou Transformativa, incorporando pro- 
fissionais de outras áreas e rompendo com a dinâmica hermética e burocrática do sistema judicial, sem ferir garantias, quando é implementada tem trazido resultados bastante satisfatórios, mas ainda dependentes da boa vontade e da adesão muitas vezes solitária de alguns profissionais do direito mais abertos à experimentação de novas práticas (MINISTÉRIO DA JUSTIÇA, 2005).

Vinculada a essa abertura para novos mecanismos de administração de conflitos, mais ou menos vinculados ao sistema de justiça formal, é preciso também investir na criação de uma nova cultura judiciária, que passa pela adoção de novos modelos de recrutamento e formação dos operadores do direito, assim como pela construção de indicadores confiáveis sobre a atividade do Poder Judiciário e a efetivação de mecanismos de controle externo sobre a administração da Justiça, que não interfiram evidentemente no conteúdo das decisões, mas permitam avançar em termos de transparência e controle público sobre a atividade judicial.

Em relação às punições, as políticas de descarcerização, para que sejam efetivas e passem a contar com o apoio público, devem ser acompanhadas de mecanismos eficientes para a aplicação e o controle das alternativas ao cárcere, podendo ter como referência o trabalho desenvolvido pelo Setor Psicossocial da Vara de Execução de Penas e Medidas Alternativas de Porto Alegre, pioneiro e exemplar na constituição de uma rede social de acolhimento e acompanhamento dos prestadores de serviço à comunidade. Aliadas a políticas de redução dos danos causados pelo encarceramento, que se colocam no lugar do mito da ressocialização no sistema prisional, apostando especialmente na melhoria das condições carcerárias e nas políticas de acolhimento ao egresso, permitem vislumbrar um caminho emancipatório em meio aos brados de incapacitação e intolerância.

A guisa de conclusão, é possível afirmar que, se as evidências mais explícitas apontam para uma perspectiva pessimista de obscurantismo social e insegurança coletiva, propícia a dinâmicas de intolerância e arbítrio, disseminando no imaginário coletivo a descrença no equacionamento pacífico dos conflitos sociais, um olhar mais atento e apurado é capaz de vislumbrar, nos interstícios do tecido social, o desenvolvimento e a expansão dos contra-poderes capazes de produzir, de forma fragmentária porém constante, a reinvenção de formas de sociabilidade solidárias e emancipatórias, capazes de trazer resultados surpreendentes na redução da violência.

Recebido em 25.10.2005.

Aprovado em 21.12.2005. um diagnóstico da violência urbana. Rio de Janeiro: Garamond, 1998, p. 227-246.

Monopólio estatal da violência na sociedade brasileira contemporânea. In: MICELI, S. (Org.). O que ler na Ciência Social brasileira. São Paulo: ANPOCS/Sumaré/CAPES, 2002, p. 267-309.

CASTELLS, M. A sociedade em rede. São Paulo: Paz e Terra, 1999.

GARLAND, D. The culture of control - crime and social order in contemporary society. Oxford: Oxford University Press, 2001.

KANT DE LIMA, R.; MISSE, M.; MIRANDA, A. P. Violência, criminalidade, segurança pública e justiça criminal no Brasil: uma bibliografia. BIB, Revista brasileira de informação bibliográfica em Ciências Sociais, ANPOCS, Rio de Janeiro, n. 50 , p. 45-124, 2. semestre de 2000.

MINISTÉRIO DA JUSTIÇA. Acesso à justiça por sistemas alternativos de administração de conflitos. Brasília: MJ, 2005.

WACQUANT, L. As prisões da miséria. Rio de Janeiro: Jorge Zahar Editor, 2001.

ZACCHI, J. M. Prevenção da violência: avanços e desafios na ordem do dia. In: BEATO FILHO, C. C. et al. Das políticas de segurança pública às políticas públicas de segurança. São Paulo: ILANUD, 2002, p. $41-56$.

ZALUAR, A. Para não dizer que não falei de samba: os enigmas da violência no Brasil. In: SCHWARCZ, L. M. (Org.). V. 1. História da vida privada no Brasil. São Paulo: Companhia das Letras, 1998, p. 245-315.

. Integração perversa: pobreza e tráfico de drogas. Rio de Janeiro: FGV, 2004.

\section{Rodrigo Ghiringhelli de Azevedo \\ rgdeazevedo@uol.com.br}

Pontifícia Universidade Católica do Rio Grande do SulPUCRS

Faculdade de Direito.

Av. Ipiranga, 6681

Prédio 11, Sala 1030 - Parthenon

Porto Alegre - Rio Grande do Sul

CEP: 90619-900

\section{Referências}

ADORNO, S. O gerenciamento público da violência urbana: a justiça em ação. In: PINHEIRO, P. S. et al. São Paulo sem medo: 